of $90 \mathrm{~mm}$. Hg or more), and as being pre-eclamptic when there was proteinuria in addition to hypertension.

In the normotensive women oedema, mainly of the legs, increased with age, being present in $14 \%$ of those under 20 years of age and in $29 \%$ of those over 30 . Preliminary evidence suggested that women who had been oedematous in one pregnancy were twice as likely to develop oedema in a subsequent pregnancy as those who did not have this sign. Women too heavy for their height at 20 weeks of pregnancy were more likely to have oedema, usually of the generalized type, than those of average weight or less. If overweight women gained weight at the rate of $1.2 \mathrm{lb}$. ( $545 \mathrm{~g}$.) or more per week from 30 to 36 weeks of pregnancy, there was a $42 \%$ chance that they would have generalized oedema and a $24 \%$ chance that they would develop oedema of the legs. When the rate of weight gain was less, so was the chance of developing oedema. It should be emphasized that these were the changes found in normotensive women.

When the blood pressure rose above $90 \mathrm{~mm}$. Hg the incidence of oedema, particularly of the generalized form, rose too, and such generalized oedema was even more likely when there was proteinuria as well. Oedema of some kind was present in $35 \%$ of normotensive women, $65 \%$ of hypertensive, and $85 \%$ of those with pre-eclampsia as defined. It is perhaps worth noting the considerable numbers of women who did not have clinically recognizable oedema even when they had hypertension with or without proteinuria.

In general, women with oedema tended to have larger babies than those who did not have oedema, though the difference was only $0.17 \mathrm{lb}$. $(77 \mathrm{~g}$.). The prematurity rate was, on the average, less when there was oedema, especially of the legs, while the perinatal mortality rate was the same whether there was oedema or not. The conclusion the authors reach is that "Oedema, in the absence of other evidence of pre-eclampsia, is associated with a slight advantage in terms of birthweight and incidence of low birthweight, and is not associated with any disadvantage in terms of perinatal mortality. To that extent, it is possible to affirm that oedema in pregnancy is not necessarily harmful and unphysiological." This careful investigation therefore begins to put oedema in perspective.

Hytten, Thomson, and N. Taggart ${ }^{2}$ investigated total body water in pregnancy. In 93 patients at least three readings of total body water were made in pregnancy and one 6 to 8 weeks after delivery, all the patients being clinically normal. The mean body water gained in pregnancy amounted to $8.5 \mathrm{~kg}$. Between 10 and 38 weeks of pregnancy the gain in body water was $6.84 \mathrm{~kg}$. in women with no oedema, 7.19 $\mathrm{kg}$. in those with oedema of the legs, and $9.80 \mathrm{~kg}$. in those with generalized oedema. It seems probable that those without oedema held between 1 and 2 litres of water in the extracellular spaces. The women with generalized oedema would appear to hold a further 3 litres somewhere which cannot be accounted for in the products of conception, the uterus, or elsewhere. Such women can be essentially normal, being healthy themselves and having normal babies. If the weight of the total body water gained is deducted from the total gain in weight, the "dry weight" gained can be estimated. When this is done it is found that overweight patients put on less "dry weight" than do those who are

\footnotetext{
Thomson, A. M., Hytten, F. E., and Billewicz, W. Z., 9. Obstet. Gynaec. Brit. Cwlth, 1967, 74, 1.

- Hytten, F. E., Thomson, A M., and Taggart, Nan, ibid., 1966, 73, 553.

_ _ ibid., 1966, 73, 714
}

of average weight for height or underweight. This " dry weight" is probably mainly fat when it cannot be accounted for in other known factors of the total weight gain. The conclusion seems to be that those women who have large fat stores already do not store much extra in pregnancy, while those with small fat stores lay down some more fat.

Hytten and Thomson ${ }^{3}$ measured total body water in six patients who developed pre-eclampsia as shown by a rise in blood pressure, proteinuria, and some oedema. The amount gained was within the limits found in normal women without pre-eclampsia, though the rate of gain of water in the last ten weeks of pregnancy was faster than in normal women with generalized oedema.

It is still not easy to assess the significance of oedema in the individual pregnant patient, but this work shows that age, oedema in a previous pregnancy, site of oedema, weight-forheight ratio, blood pressure, proteinuria, and rate of weight gain may all have to be taken into account. Oedema of itself would not seem to be invariably a bad prognostic sign and indeed might signify a slightly better prognosis for the baby when all other factors are considered. This work helps to clarify the relationship between oedema and increase in total body water in pregnancy, but the difference between normal and pre-eclamptic pregnancy in terms of water metabolism is still conjectural.

\section{Investigating Hypertension}

In general the significance of a patient's renal lesion to his hypertension is difficult to decide. For instance, renal-artery stenosis may occur with $^{1}$ or without $^{2}$ hypertension. Thus there is still no single reliable investigation for selecting those hypertensive patients with unilateral renal disease who may be expected to benefit from surgery.

The help of various complex inpatient investigations is sought before resorting to surgical operation. They include aortography, possibly with renal-function studies of each kidney, assay of pressor substances in systemic or renal circulation, angiotensin-infusion tests, studies of renal blood flow, and bilateral renal biopsy. These are formidable tests to put any patient through, and it is not easy to find agreement on which patients should be subjected to them. H. W. Smith $^{3}$ estimated the incidence of curable renal hypertension to be at most $2 \%$ of all hypertensive patients. This fairly gloomy picture is confirmed by $M$. J. Chamberlain and J. A. Gleeson, ${ }^{4}$ who found that in a series of patients subjected to aortography the number permanently benefited by surgery was unduly small in relation to the morbidity of the investigation and later operation. But a higher proportion of cases of correctable renal hypertension has been reported by $M$. E. DeBakey and colleagues ${ }^{5}$ and E. F. Poutasse. ${ }^{\circ}$ A compromise figure, $5-10 \%$, of renovascular hypertension has been proposed by M. H. Maxwell and G. B. Prozan, ${ }^{7}$ who thought that the great majority of such patients could benefit from surgery. In Britain renal-artery stenosis has been reported in $10 \%$ of hypertensive patients at aortography, ${ }^{8}$ and the surgical treatment of carefully selected patients has certainly been rewarding. 910

Viewed against this background any advance in the accuracy of outpatient screening tests to select patients for more complex inpatient studies would be welcome. If the 
small number of potentially curable patients could be detected with some certainty at this stage many others might be spared fruitless further investigation. The standard intravenous pyelogram (I.V.P.) is not adequate to this end, failing to select about half of those with renovascular hypertension. ${ }^{511}$ It gives excellent information about important correctable lesions like unilateral hydronephrosis, pyelonephritis, or tuberculosis, but these play only a small part in renal hypertension. In cases of unilateral renal ischaemia major structural changes in kidney or ureter may be evident. Attempts to improve the diagnostic value of the I.V.P. have been based on studies of asymmetric patterns in the excretion of contrast medium deriving from the selective sodium and water reabsorption in the ischaemic kidney. ${ }^{12}$

Films taken at minute intervals after the injection of contrast medium show up any delay in the appearance of contrast, and this technique has been of help in some hands. ${ }^{13}$ However, when differences between the two sides are small, perhaps a minute or less, interpretation can be difficult. ${ }^{14}$ Increased density of contrast medium due to marked reabsorption of water in the affected kidney can also cause confusion. To accentuate the asymmetry of contrast density $\mathrm{K}$. Amplatz ${ }^{15}$ proposed establishing an osmotic diuresis in the course of the I.V.P. by infusion of urea, thus allowing comparison between the rapid wash-out of contrast from the normal kidney with contrast retention in the ischaemic, oliguric kidney. The early reports of this technique of "radiological divided renal-function studies" suggested a much-improved detection rate of renovascular hypertension, with no false-negative results in the sense of failures to select patients improved by surgery, though "pseudopositive" results to the test were reported.16 17 . H. Schreiber and colleagues ${ }^{18}$ have recently laid down a range for the normal and shown that the test does not contribute

1 Lawrence, J. R., Doig, A., Knight, I. C. S., MacLaren, I. F., and Donald, K. W., Lancet, 1964, 1, 62.

2 Holley, K. E., Hunt, J. C., Brown, A. L., Kincaid, O. W., and Sheps, S. G., Amer. F. Med., 1964, 37, 14 .

3 Smith, H. W., f. Urol. (Baltimore), 1956, 76, 685.

- Chamberlain, M. J., and Gleeson, J. A., Lancet, 1965, 1, 619.

- DeBakey, M. E., Morris, G. C., Morgen, R. O., Crawford, E. S., and Cooley, D. A., Amer. F. Surg., 1964, 107, 84 .

- Poutasse, E. F., ibid., 1964, $107,97$.

- Maxwell, M. H., and Prozan, G. B., Progr. cardiovasc. Dis., 1962, 5, 81.

- Sutton, D., Brunton, F. J., and Starer, F., Clin. Radiol., 1961, 12, 80.

- Brown, J. J., Owen, K., Peart, W. S., Robertson, J. I. S., and Sutton, D., Brit. med. F., 1960, 2, 327.

10 Owen, K., Brit. f. Urol., 1964, 36, 7.

11 Spencer, F. C., Stamey, T. A., Bahnson, H. T., and Cohen, A., Ann. Surg., 1961, 154, 674.

12 Mueller, C. B., Surtshin, A., Carlin, M. R., and White, H. L., Amer. F. Physioi., 1951, 165, 411 .,

1s Maxwell, M. H., Gonick, H. C., Wiita, R., and Kaufman, J. J., New Engl. Э. Med., 1964, 270, 213.

14 Fenton, S. S. A., Lyttle, J. A., and Pantridge, J. F., Lancet, 1966, 2, 117 .

18 Amplatz, K., Radiology, 1962, 79, 807.

16 Stejskal, R. E., Staub, E. V., Loken, M. K., and Amplatz, K., Amer. 7. Roentgenol., 1964, 92, 1397.

17 Schreiber, M. H., Sarles, H. E., Herring, M. E., and Remmers, A. R., New Engl. F. Med., 1964, 270, 1223.

18 Schreiber, M. H., Remmers, A. R., Sarles, H. E., and Smith, G. H. Amer. Э. Roentgenol., 1966, 98, 88.

10 Witten, D. M., Hunt, J. C., Sheps, S. G., Greene, L. F., and Utz, D. C., ibid., 1966, 98, 114.

20 Doig, A., Lawrence, J. R., Philp, T., Tothill, P., and Donald, K. W., Brit. med. ₹., 1963, 1, 500 .

21 Farmelant, M. H., Lipetz, C. A., Bikerman, V., and Burrows, B. A., Amer. F. Surg., 1964, 107, 50.

22 Andrews, D., Parsons, V., and Roebuck, E. J., Brit. F. Radiol., 1965, $38,527$.

23 Luke, R. G., Briggs, J. D., Kennedy, A. C., and Stirling, W. B., Quart. f. Med., 1966, 35, 237.

s Kennedy, A. C., Luke, R. G. Briggs, J. D., and Stirling, W. B., Lancet, 1965, 2, 963. to the diagnosis of bilateral renovascular disease. The whole place of "wash-out" pyelograms in this field has now been questioned by D. M. Witten and his colleagues, ${ }^{19}$ who used mannitol infusion during the I.V.P. in preference to urea, to avoid the latter's potential hazards.

If the success rate of the intravenous pyelogram in the diagnosis of renovascular hypertension can be increased only from $50 \%$ to between $60 \%$ and $70 \%$ by these various refinements it is reasonable to look in other directions for a complementary outpatient screening test of individual renal function. After an uncertain start the hippuran radioisotope renogram has for some time been used with success. ${ }^{20-22}$ The careful work of R. G. Luke and his colleagues ${ }^{23}$ has now confirmed it as a simple, safe, and rapid investigation in the search for renovascular hypertension. Performed with care and used in conjunction with an initial I.V.P., the incidence of false-negative and false-positive assessments can be kept below $5 \% .24$ This is a fairly good rate of detection, and one that materially helps to prevent fruitless further investigation.

On present-day evidence the best way of selecting those hypertensive patients who may benefit from further inpatient investigation into a renal cause of their disease is to perform an intravenous pyelogram, supplemented by radiographs during the first five minutes of the examination, and to follow this with a radioisotope renogram.

\section{Mediastinal Emphysema}

Mediastinal emphysema has the distinction of being one of the very few conditions which enable the heart beats to be heard from the foot of the bed. With the stethoscope the "crunching" sound described by L. Hamman" is usually heard best down the left border of the heart; it varies in intensity and may be absent. If the sign is associated with subcutaneous emphysema of the neck or chest the diagnosis of mediastinal emphysema is virtually certain. The radiological appearances are characteristic, showing a small air space running parallel to the left, and sometimes the right, border of the heart. There may be an associated pneumothorax.

Air may enter the mediastinum by any of several routes. The commonest, as in so-called benign mediastinal emphysema, seems to be through the pulmonary alveoli, when a small rupture causes a pressure gradient between the alveoli and adjacent connective tissue. ${ }^{2}$ The mechanism of such a gradient is obscure, but it seems at times to be precipitated by pulmonary emphysema, asthma, pneumonia, or childbirth. Once the air has entered the tissue it takes the line of least resistance and passes along the perivascular sheaths to the mediastinum and thence to the subcutaneous tissue. Ordinarily it does not extend far beyond the neck and in the benign form subsides within a few days. But occasionally the air spreads beyond the neck to the hand, arms, trunk, and even the legs, in which case there is a danger of suffocation. The other possible complication is the so-called " malignant" form of mediastinal emphysema, in which the pressure of air

\footnotetext{
1 Hamman, L., Trans. Ass. Amer. Phycns, 1937, 52, 311.

'Macklin, M. T., and Macklin, C. C., Medicine (Baltimore), 1944, 23, 281.

3 Gray, J. M., and Hanson, G. C., Thorax, 1966, 21, 325.
} 